\title{
Kc167, a widely used Drosophila cell line, contains an active primary piRNA pathway
}

\author{
NICHOLAS VRETTOS, ${ }^{1}$ MANOLIS MARAGKAKIS, ${ }^{1}$ PANAGIOTIS ALEXIOU, and ZISSIMOS MOURELATOS \\ Department of Pathology and Laboratory Medicine, Division of Neuropathology, Perelman School of Medicine, University of Pennsylvania, \\ Philadelphia, Pennsylvania 19104, USA
}

\begin{abstract}
PIWI family proteins bind to small RNAs known as PIWI-interacting RNAs (piRNAs) and play essential roles in the germline by silencing transposons and by promoting germ cell specification and function. Here we report that the widely used Kc167 cell line, derived from Drosophila melanogaster embryos, expresses piRNAs that are loaded to Aub and Piwi. Kc167 piRNAs are produced by a canonical, primary piRNA biogenesis pathway, from phased processing of precursor transcripts by the Zuc endonuclease, Armi helicase, and dGasz mitochondrial scaffold protein. Kc167 piRNAs derive from cytoplasmic transcripts, notably tRNAs and mRNAs, and their abundance correlates with that of parent transcripts. The expression of Aub is robust in Kc167, that of Piwi is modest, while Ago3 is undetectable, explaining the lack of transposon-related piRNA amplification by the Aub-Ago3, ping-pong mechanism. We propose that the default state of the primary piRNA biogenesis machinery is random transcript sampling to allow generation of piRNAs from any transcript, including newly acquired retrotransposons. This state is unmasked in Kc167, likely because they do not express piRNA cluster transcripts in sufficient amounts and do not amplify transposon piRNAs. We use Kc167 to characterize an inactive isoform of Aub protein. Since most Kc167 piRNAs are genic, they can be mapped uniquely to the genome, facilitating computational analyses. Furthermore, because Kc167 is a widely used and well-characterized cell line that is easily amenable to experimental manipulations, we expect that it will serve as an excellent system to study piRNA biogenesis and piRNA-related factors.
\end{abstract}

Keywords: piRNA; Kc167; Aubergine; Piwi; Zucchini; tRNA; GASZ; Armitage; MOV10L1; Argonaute; transposon

\section{INTRODUCTION}

The piRNA pathway is active in the germline of all metazoans and functions primarily as a transposon defense system (Aravin et al. 2003; Vagin et al. 2006; Hirakata and Siomi 2016). piRNAs are loaded to the PIWI subfamily of Argonaute proteins and form effector complexes that negatively regulate transposon expression (Siomi et al. 2011). In Drosophila melanogaster, piRNAs are 23-29 nucleotides (nt) long and bind to Piwi, Aubergine (Aub) or Argonaute 3 (Ago3) (Cox et al. 1998; Harris and Macdonald 2001; Brennecke et al. 2007; Gunawardane et al. 2007; Li et al. 2009). Arginines close to the $\mathrm{N}$ terminus of PIWI proteins are symmetrically dimethylated (sDMA) by the methylosome and become ligands for Tudor-domain containing proteins (Tdrds) (Kirino et al. 2009; Nishida et al. 2009; Kirino et al. 2010; Liu et al. 2010; Chen et al. 2011). Tdrds are essential for the precise execution of piRNA biogenesis steps and for piRNA functions (Nishida et al. 2009; Kirino et al. 2010; Siomi et al. 2010; Chen et al. 2011; Pek et al. 2012;

\footnotetext{
${ }^{1}$ These authors contributed equally to this work

Corresponding author: mourelaz@uphs.upenn.edu 116.
}

Sato et al. 2015; Webster et al. 2015). Notably, interactions between methylated Aub and its ligand Tudor form oocyte germ granules that trap mRNAs in a piRNA-dependent manner (Vourekas et al. 2016). Germ granule mRNAs specify primordial germ cells in the developing embryo (Illmensee and Mahowald 1974; Lehmann and Ephrussi 1994; Williamson and Lehmann 1996; Rangan et al. 2009) and at the same time Aub-piRNAs propagate an RNA immune response against transposons (Brennecke et al. 2008; de Vanssay et al. 2012; Vourekas et al. 2016).

piRNAs derive from long, noncoding RNAs transcribed from intergenic regions known as piRNA clusters; from active transposons; and in fewer cases from tRNAs; and mRNAs, the latter known as genic piRNAs (Brennecke et al. 2007; Malone et al. 2009; Hirakata and Siomi 2016). piRNA clusters, such as flamenco (flam) and $42 \mathrm{AB}$, contain primarily antisense transposon sequences and give rise to most piRNAs; clusters contain fragmented or translocation-

\footnotetext{
(C) 2016 Vrettos et al. This article is distributed exclusively by the RNA Society for the first 12 months after the full-issue publication date (see http://rnajournal.cshlp.org/site/misc/terms.xhtml). After 12 months, it is available under a Creative Commons License (Attribution-NonCommercial 4.0 International), as described at http://creativecommons.org/licenses/ by-nc/4.0/.
} 
defective transposons that were deposited over the course of evolution and represent an RNA memory of past transposon exposures (Brennecke et al. 2007; Mevel-Ninio et al. 2007; Czech and Hannon 2016; Hirakata and Siomi 2016).

Upon exiting the nucleus, primary piRNA precursors are processed on the surface of mitochondria, in an area known as nuage by the conserved Zuc endonuclease (in mice known as mZuc or mitoPLD), which excises piRNA intermediate fragments in a phased, 5'-3' direction (Pane et al. 2007; Ipsaro et al. 2012; Nishimasu et al. 2012; Han et al. 2015; Mohn et al. 2015). Other conserved, primary piRNA processing factors include the RNA helicase Armitage (Armi; known as MOV10L1 in mice) and the mitochondrial protein dGASZ (Cook et al. 2004; Ma et al. 2009; Haase et al. 2010; Olivieri et al. 2010; Saito et al. 2010; Handler et al. 2013). In mice, the piRNA Loading and Cleavage Complex (Vourekas et al. 2015), whose core components are an empty PIWI protein, MOV10L1 (Frost et al. 2010; Zheng et al. 2010) and mZuc (Huang et al. 2011; Watanabe et al. 2011; Ipsaro et al. 2012; Nishimasu et al. 2012) couples piRNA processing with PIWI loading (Vourekas et al. 2015). MOV10L1 unwinds and feeds the long piRNA precursor to be cleaved by mZuc, and piRNA intermediate fragments containing $5^{\prime}-\mathrm{U}$ are preferentially loaded to empty PIWI (Vourekas et al. 2015). If needed, these fragments are trimmed by the $3^{\prime}$-exonuclease Trimmer (Izumi et al. 2016) that associates with mitochondrial protein TdrKH (Honda et al. 2013; Saxe et al. 2013; Izumi et al. 2016). Mature piRNAs loaded to PIWI are finally $2^{\prime}-O$ methylated at their $3^{\prime}$-ends (Kirino and Mourelatos 2007b; Ohara et al. 2007) by the Hen1 methyltransferase (Yu et al. 2005; Horwich et al. 2007; Kirino and Mourelatos 2007a; Saito et al. 2007; Lim et al. 2015). In Drosophila, primary piRNAs are loaded predominantly onto Piwi and Aub (Brennecke et al. 2007; Gunawardane et al. 2007; Hirakata and Siomi 2016). Piwi-bound piRNAs shuttle to the nucleus and repress transcription of transposons (Sienski et al. 2015; Czech and Hannon 2016; Iwasaki et al. 2016). Aub-bound piRNAs scavenge for complementary transposon mRNA transcripts and cleave them between nucleotide positions 10 and 11 producing the $5^{\prime}$-ends of new "secondary" piRNAs, which are then loaded to Ago3, trimmed, and methylated (Czech and Hannon 2016). Ago3-bound piRNAs are thus mostly sense to transposons, do not have a preference for a specific nucleotide in the first position but typically contain an $\mathrm{A}$ at position 10 (Czech and Hannon 2016). Ago3-piRNAs can subsequently target piRNA cluster or antisense transposon transcripts generating more piRNA templates that are loaded to Aub, supporting a model for continuous transposon sequence capture and consumption, termed ping-pong cycle (Brennecke et al. 2007; Gunawardane et al. 2007; Czech and Hannon 2016). Aub and Ago3 cleavage also initiates a downstream process of phased, Zuc-cleavage events and these newly formed piRNAs are preferentially loaded onto Piwi (Han et al. 2015; Mohn et al. 2015; Senti et al. 2015).
Cell lines that endogenously express PIWI proteins and piRNAs are incredibly important to study molecular mechanisms of piRNA biogenesis and function. The follicle cells that surround Drosophila ovaries, although of somatic origin, express primary piRNAs bound to Piwi and protect the organism from gypsy and other retrotransposons; they do not express Aub, Ago3 or secondary piRNAs (Lau et al. 2009; Saito et al. 2009). Progenitors from these cells, expressing Piwi and primary piRNAs, had been successfully cultured ex vivo and named OSC (Niki et al. 2006; Lau et al. 2009; Saito et al. 2009). Loss of lethal (3) malignant brain tumor [l(3) $m b t]$ gene in Drosophila leads to formation of malignant brain tumors that ectopically express multiple PIWI pathway genes that promote tumorigenesis (Janic et al. 2010). Interestingly, Aub and Ago3 expression and secondary piRNA production can be reanimated in OSC cells upon deletion of l(3)mbt (Sumiyoshi et al. 2016). Ectopic expression of Piwi and primary piRNAs is also notable in WRR-1 cells, which are derived from somatic Drosophila cells transformed by combining inactivation of Warts kinase with the oncogenic form of Ras (Fagegaltier et al. 2016). Additionally, the ovarian cell-derived culture BmN4 from Bombyx mori expresses Piwi and Ago3 paralogs loaded with piRNAs (Kawaoka et al. 2009).

In this study, we show that the widely used Kc167 cells possess a significant part of the primary piRNA machinery. The Kc167 cell line was derived from disaggregated $8-12 \mathrm{~h}$ Drosophila embryos (Echalier and Ohanessian 1969), exhibits a hemocyte-like mRNA expression pattern and is one of the cell lines used by modENCODE (Cherbas et al. 2011; Eaton et al. 2011; Brown and Celniker 2015). Kc167 cells are easy to grow and transfect, do not require fly extract supplement, and they have been used extensively in RNAi screens (Yin et al. 2013). We report that Kc167 cells express piRNAs that are bound to Aub and Piwi and have features similar to germline genic piRNAs. We show that piRNA biogenesis in Kc167 cells is phased and dependent on Armi, Zuc, and dGasz. Interestingly, we find that the majority of Kc167 piRNAs derive from mRNAs and tRNAs and not from transposons. Furthermore, we use the Kc167 system to detect and characterize a shorter Aub isoform that is inactive in the piRNA pathway. We propose that Kc167 serves as an excellent system to study piRNA biogenesis and piRNA-related factors.

\section{RESULTS}

\section{Kc167 cells express piRNAs bound on Aub and Piwi}

We sought to identify established cell lines, which naturally express Aub-bound piRNAs as a system to study Aub, piRNA biogenesis and functions. We noticed that Aub peptides were obtained from Kc167 cells in mass spectrometry experiments designed to identify components of the Drosophila spliceosome (Herold et al. 2009), prompting us 
to investigate whether Aub and other factors of the piRNA pathway are present in these cells. Western blot (WB) analysis of Kc167 cell lysates along with ovary lysate, as a control, revealed clear and strong signals for Aub and Armi, and a clear but weaker signal for Piwi (Fig. 1A). By immunofluorescence, we detected Aub localizing diffusely throughout the cytoplasm of Kc167 cells (Supplemental Fig. S1). As an orthogonal approach, we performed immunoprecipitations (IPs) for Aub, Piwi, and Armi from Kc167 lysates and confirmed their expression by mass spectrometry of silverstained protein bands (Supplemental Table S1). In contrast, WBs for Ago3, Vasa, and Tudor showed that these proteins are not expressed (Ago3, Tud) or are barely detectable (Vasa) in Kc167 cells (Fig. 1A).
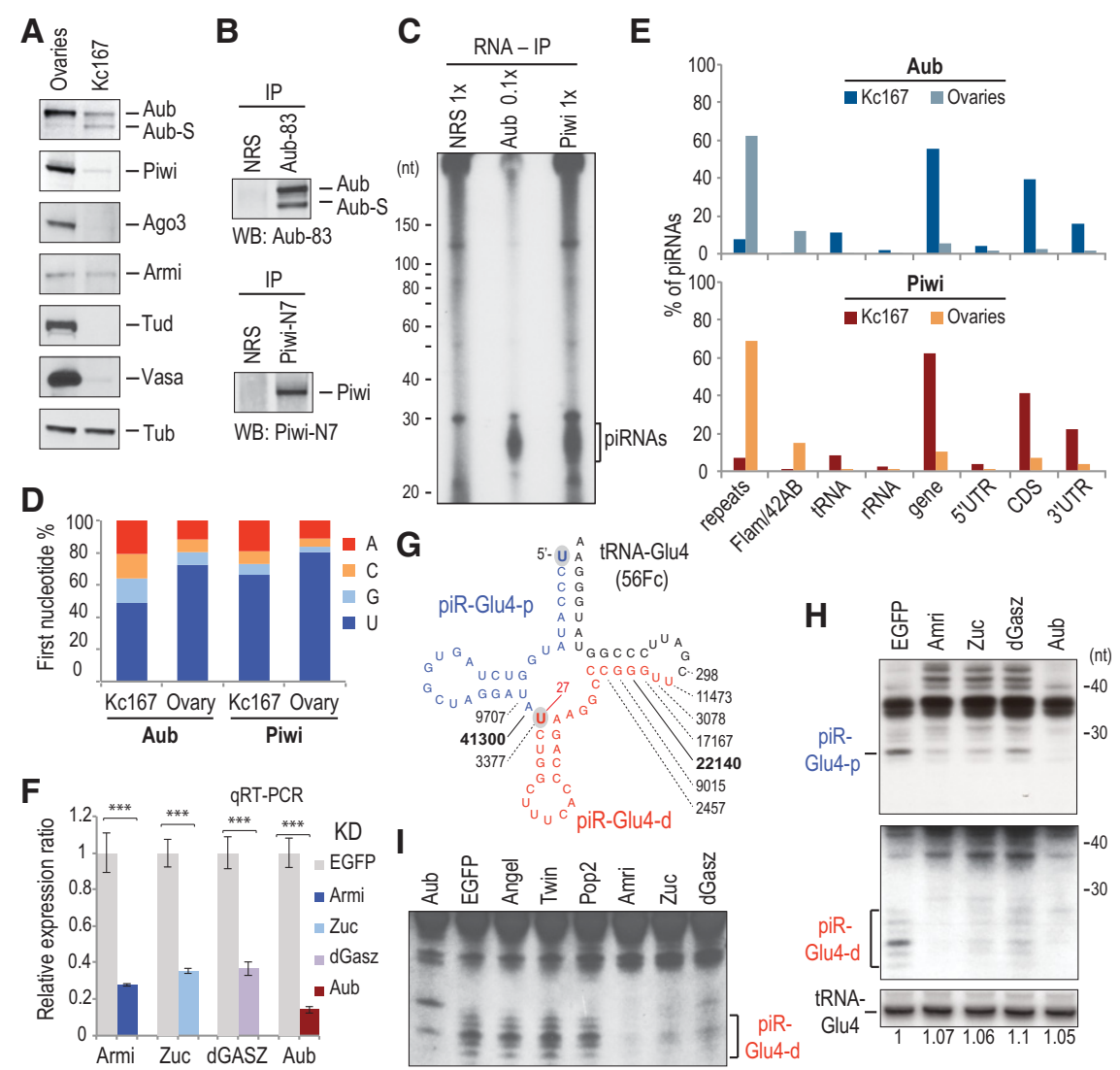

FIGURE 1. Kc167 cells produce primary piRNAs that are loaded to Aub and Piwi. (A) Western blots (WB) for indicated piRNA factors in $y w$ ovaries and Kc167. (B) WB of Aub and Piwi immunoprecipitates from Kc167. Nonimmune rabbit serum (NRS) served as negative control. (C) Aub- and Piwi-bound RNAs were dephosphorylated, 5'-end radiolabeled, and resolved by 15\% Urea-PAGE. $(D)$ Composition of the first nucleotide of Aub and Piwi piRNAs in Kc167 and $y w$ ovaries. (E) Genomic distribution for Aub and Piwi piRNAs in Kc167 and $y w$ ovaries. $(F)$ Expression of indicated mRNAs after knockdowns $(\mathrm{KD})$ relative to EGFP KD (negative control) assessed by qRT-PCR. Error bars represent one standard deviation ( \pm S.D.; $n=3$; [ $\left.{ }^{* * *}\right] P$-value $<0.005$, one-sided $t$-test). ( $G$ ) Secondary structure of tRNA-Glu4 $(56 \mathrm{Fc})$ and derived piRNAs shown in color. Numbers indicate the frequency of piRNA $3^{\prime}$-ends at each position. Gray shaded circles denote the most common $5^{\prime}$-end of the proximal and distal piRNAs. $(H)$ Northern blots (NB) for piR-Glu4-p (upper panel) and piR-Glu4-d (middle panel) in indicated knockdown cells. Total RNAs were resolved by 15\% Urea-PAGE. Mature tRNA levels (lower panel) remained unchanged. (I) NB for piR-Glu4-d in indicated knockdown cells. Total RNAs were resolved by $17.5 \%$ Urea-PAGE.
To determine whether small RNAs are bound to Aub and Piwi, we performed IPs from Kc167 lysates; as shown in Figure 1B, WBs of the immunoprecipitates confirmed the presence of Aub and Piwi and uncovered a shorter Aub iso(Aub-S; see below). We then extracted, dephosphory$5^{\prime}$-end radiolabeled bound RNAs and resolved (PAGE). As shown in Figure 1C, small RNAs corresponding in size to piRNAs are bound to Aub and Piwi. To characterize RNAs further, we constructed cDNA libraries by eming a protocol based on a single linker ligation step and lowed by sequence by synthesis, generating 90 and 105 lowed by sequence by synthesis, generating $\sim 90$ and $\sim 105$ Kc167 Aub and Piwi libraries, respectively. Data from an ovarian Piwi library conan ovarian Aub piRNA library published recently (Vourekas et al. 2016) were used for comparison. The $5^{\prime}-\mathrm{U}$ preference (Fig. 1D) and length distribution (Fig. 2A) of Kc167 Aub and Piwi piRNAs are similar to ovarian piRNAs. Unlike ovarian piRNAs, which predominantly align to repeats and piRNA clusters such as $42 \mathrm{AB}$ and flam, most of Kc167 Aub and Piwi piRNAs are genic and are derived from mRNAs and mature tRNAs (Fig. $1 \mathrm{E})$. The pattern of piRNA generation from mRNAs in Kc167, with most piRNAs originating from coding sequences (CDS) followed by $3^{\prime}$-untranslated regions $\left(3^{\prime}\right.$-UTRs $)$ and $5^{\prime}$-UTRs, indicates that the entire mRNA is subject to processing (Fig. 1E).

\section{Kc167 piRNA biogenesis is dependent on Armi, Zuc, and dGasz}

Two of the most highly sequenced Kc167 Aub piRNAs are derived from tRNA Glu4 56Fc. The $5^{\prime}$-end of the proximal piRNA (piR-Glu4-p) coincides with the $5^{\prime}$-end of the mature tRNA while the $5^{\prime}$ end of the distal piRNA (piR-Glu4-d) starts from nucleotide position 27 (Fig. $1 G)$. Using these piRNAs as examples, we sought to investigate whether piRNA biogenesis in Kc167 is dependent on Armi, Zuc, and dGasz, factors that are essential for primary piRNA processing. We performed knockdowns in Kc167 using dsRNAs against armi, zuc, dgasz, aub and confirmed $>60 \%$ reduction of respective mRNA levels by qRT-PCR; EGFP knockdown was used as negative 

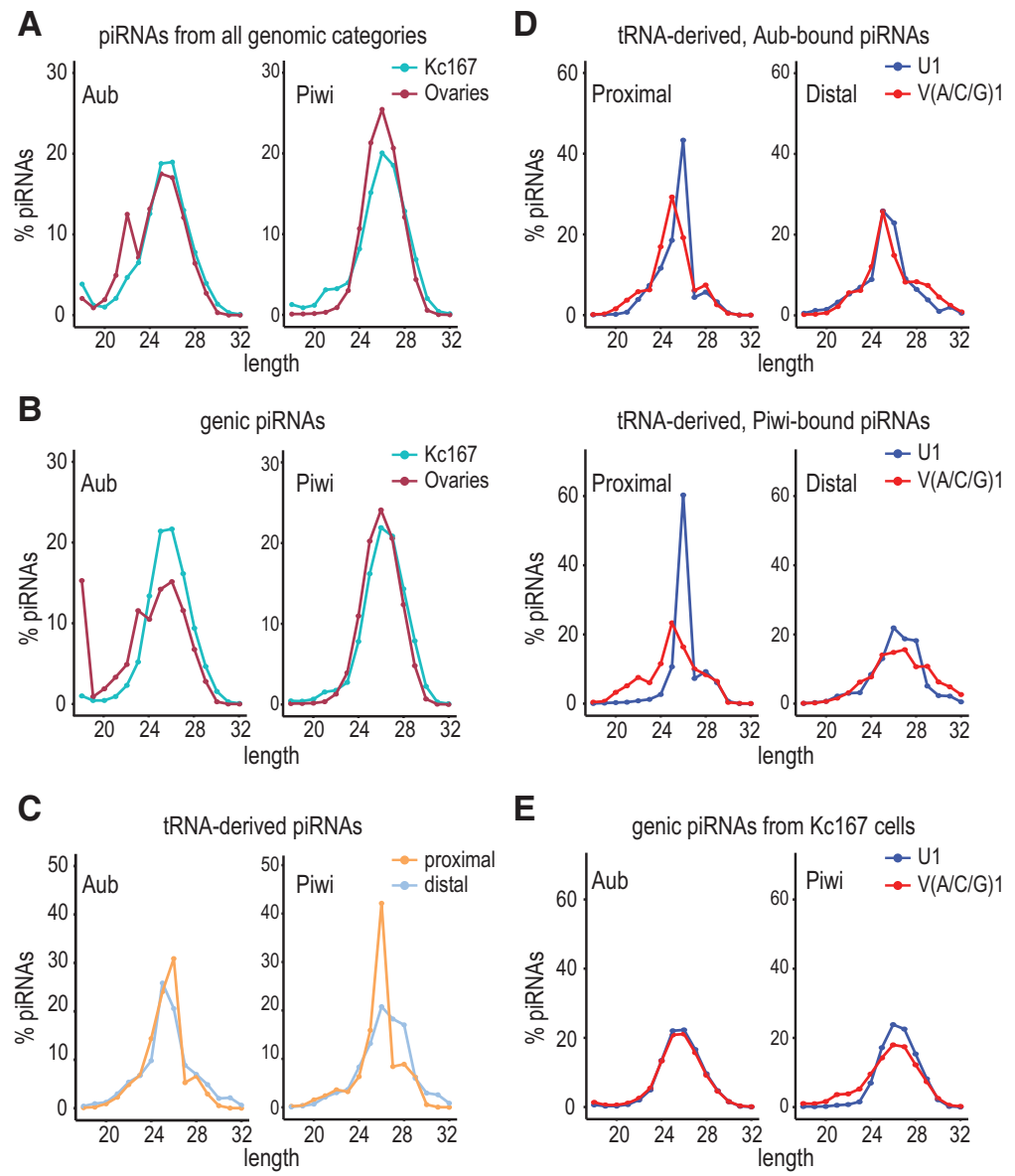

FIGURE 2. Proximal and distal tRNA-derived piRNAs display different length distribution. ( $A$, $B)$. Length distribution of Aub and Piwi piRNAs in Kc167 and $y w$ ovaries for all piRNAs $(A)$ and for piRNAs that map to gene exons $(B)$. (C) Length distribution of Kc167 Aub and Piwi tRNAderived piRNAs. Orange and light blue lines correspond to proximal and distal piRNAs, respectively. $(D)$ Length distribution of Kc167 Aub and Piwi tRNA-derived piRNAs. Blue and red lines correspond to piRNAs that start with a $\mathrm{U}$ or A/C/G, respectively. (E) Length distribution of Kc167 Aub and Piwi genic piRNAs. Blue and red lines correspond to piRNAs that start with a $\mathrm{U}$ or $\mathrm{A} / \mathrm{C} /$ $\mathrm{G}$, respectively.

control (Fig. 1F). We then performed Northern blots (NBs) using probes against piR-Glu4-p and piR-Glu4-d. As shown in Figure 1H, we detect robust expression of piR-Glu4-p in control Kc167 cells that appears as a single band, congruent with sequencing results, which show the presence of a predominant 26 nt species (Fig. 1G). piR-Glu4-p essentially disappears in $a u b$ knockdown or is reduced in armi, zuc, and dgasz knockdowns (Fig. 1H, upper panel). NB analysis of piR-Glu4-d shows multiple 23-28 nt bands, including a dominant one at $25 \mathrm{nt}$ (Fig. 1H, middle panel), consistent with sequencing results (Fig. 1G); these bands are eliminated in aub knockdown or markedly reduced in $\operatorname{armi}, z u c$, and dgasz knockdowns (Fig. 1H, middle panel). Mature tRNA Glu4 levels remain unchanged in all knockdown samples (Fig. 1H, lower panel). To further confirm the dependence of Kc167 piRNA biogenesis in canonical primary piRNA pathway factors, we repeated the knockdowns and included three nucleases unrelated to the piRNA pathway (Pop2,
Angel, Twin). The levels of piR-Glu4-d are drastically reduced in $a u b, a r m i, z u c$, and dgasz knocdowns but are not affected by depletion of pop2, angel, or twin (Fig. 1I; Supplemental Fig. S2). These results indicate that Kc167 piRNAs are produced by the same factors that generate germline piRNAs. Interestingly, knockdowns of aub, armi, zuc, and dgasz did not reduce cell viability or growth (data not shown) indicating that Kc167 piRNAs do not impact essential cellular pathways (at least for the duration of the knockdowns, up to $\sim 6 \mathrm{~d}$ ).

\section{tRNAs as substrates for piRNA processing}

To further analyze tRNAs as substrates for piRNA processing in Kc167, we measured the average number of piRNAs on each mature tRNA transcript. There are 292 tRNA genes annotated in the Drosophila melanogaster genome, 34 of which start with Uridine. For Aub and Piwi libraries we find that piRNAs derived from tRNAs starting with $U$, were at least sixfold and 16-fold more than tRNAs starting with any other nucleotide, respectively (Table 1), consistent with the preference of both Aub and Piwi for substrates with a $5^{\prime} \mathrm{U}$.

By comparing the lengths of Kc167 genic and tRNA-derived piRNAs, we notice that genic piRNAs have a wider length distribution than tRNA-derived ones, which are mostly 24-28 nt (Fig. 2B,C). Piwi piRNAs derived from the $5^{\prime}$-proximal region of tRNAs have a narrower length distribution than those derived from the distal part (Fig. 2C), indicating a difference in the $3^{\prime}$-end formation between these two piRNA species. Furthermore, we find that tRNA-derived piRNAs starting with $\mathrm{U}$ display a narrower length distribution for proximal piRNAs, whereas the length of the distal piRNAs is

TABLE 1. Average number of piRNAs derived from mature tRNAs starting with Uridine (34 tRNAs) or any other nucleotide (258 tRNAs)

\begin{tabular}{|c|c|c|}
\hline & \multicolumn{2}{|c|}{ Average piRNA count } \\
\hline & tRNA $5^{\prime}$-end: U & tRNA 5'-end: [ACG] \\
\hline Kc167 Aub & 8197 & 1376 \\
\hline Kc167 Piwi & 14,341 & 878 \\
\hline
\end{tabular}


independent of the $5^{\prime}$-end nucleotide content (Fig. 2D). These findings along with knockdown experiments and NB analysis of tRNA Glu4 as shown above (Fig. 1F-I) are consistent with a coupled and phased (and see below) cleavageloading model of piRNA processing. Empty PIWI binds to tRNAs that start with $5^{\prime}-\mathrm{U}$ and its footprint corresponds to the proximal piRNA that is liberated from the remainder of the tRNA after Zuc cleavage. The distal part is then loaded to another PIWI protein and further processed into a mature piRNA by Zuc and a trimming nuclease, likely Nibbler (Wang et al. 2016); the larger heterogeneity of its $3^{\prime}$-end reflects the longer tRNA portion that is subjected to trimming.

Finally, no difference in length distribution was observed when this analysis was repeated for $U$ and non- $U$ initiating piRNAs of genic origin (Fig. 2E).

\section{Kc167 Aub and Piwi piRNAs display phasing signatures}

We analyzed the position of each Aub-bound or Piwi-bound Kc167-derived piRNA relative to that of other piRNAs from the same library, by plotting the density of $5^{\prime}-5^{\prime}$ distances. We performed this analysis independently for genic and tRNAderived piRNAs. In all cases we noticed, for both Aub and
Piwi bound piRNAs, a characteristic peak around position 27 indicative of phased piRNA processing (Fig. 3A; Han et al. 2015; Homolka et al. 2015; Mohn et al. 2015). This peak is more pronounced for tRNA-derived piRNAs (Fig. 3A). Ovarian Aub and Piwi piRNA libraries serve as positive controls and validate the finding that Kc167 piRNAs display typical phasing signatures (Fig. 3A). Next, we studied the relative positioning between Piwi and Aub piRNAs. Using Aub piRNA $5^{\prime}$-ends as reference points, we detected Piwi piRNAs starting either from the same position or $27 \mathrm{nt}$ downstream (Fig. 3B). For both Aub and Piwi piRNAs, independent of their length, the most common nucleotide downstream from their $3^{\prime}$-ends is a Uridine (Fig. 3C), consistent with Zuc cleavage of the piRNA precursor before a $\mathrm{U}$ (Han et al. 2015; Mohn et al. 2015). Finally, we plotted the density of $5^{\prime}$ and $3^{\prime}$ piRNA-ends along the meta-tRNA for Aub and Piwi. Most Aub piRNAs initiate from the $5^{\prime}$-end of the tRNA and extend to the $\sim 26$ th nucleotide with a second piRNA initiation peak at the 27th nucleotide (Fig. 3D). In contrast, most Piwi piRNAs derive from the second peak, consistent with recent reports demonstrating that Piwi piRNAs initiate downstream from Aub piRNAs (Han et al. 2015; Mohn et al. 2015; Senti et al. 2015).
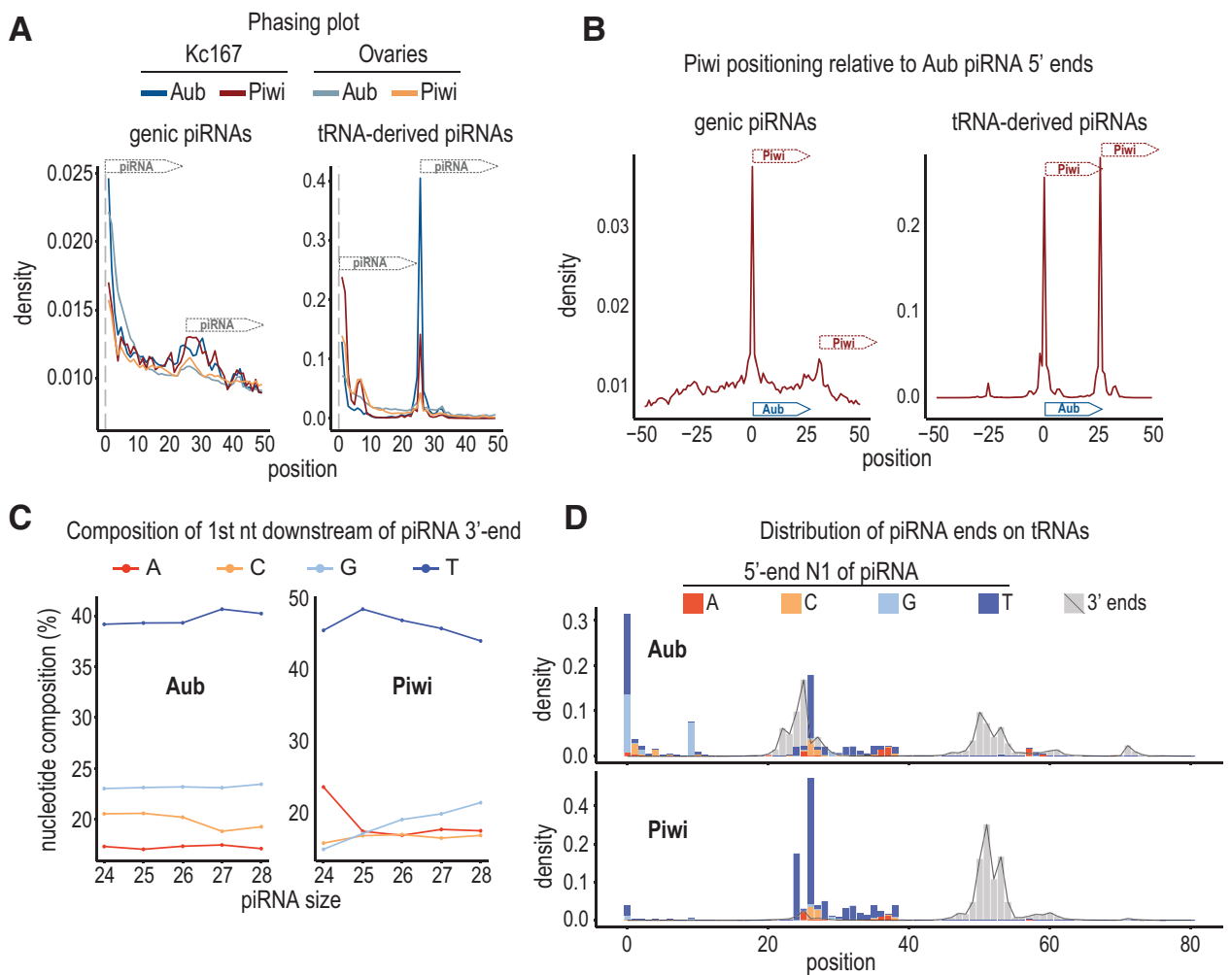

FIGURE 3. Kc167 piRNAs display phasing. (A) Density plots of $5^{\prime}-5^{\prime}$ distance between Aub piRNAs (dark and light blue lines) and Piwi piRNAs (red and orange lines) mapping in exons or tRNAs, in Kc167 and $y w$ ovaries. Arrows indicate examples of piRNA pairs whose relative positioning corresponds to the most prevalent peak in the plots. (B) Density plot of 5' $-5^{\prime}$ distance between Aub and Piwi piRNAs derived from exons or tRNAs, in Kc167. Arrows indicate examples of Aub (blue) and Piwi (red) piRNA pairs whose relative positioning corresponds to the most prevalent peak in the plots. $(C)$ Nucleotide composition of the first nucleotide downstream from the 3'-end of Kc167 Aub and Piwi genic piRNAs of various lengths. (D) Density plot of 5' and $3^{\prime}$-ends of Aub and Piwi tRNA-derived piRNAs. Colors indicate the nucleotide composition of the 5'-end. Gray shading indicates the density of the $3^{\prime}$-end. Position 0 corresponds to the $5^{\prime}$-end of mature tRNAs. 


\section{piRNA abundance correlates with mRNA expression}

To address how mRNAs are selected for piRNA processing in Kc167 cells, we tested whether there is any correlation between the numbers of piRNA reads derived from exonic regions and the expression levels of parent transcripts as assessed by RNA-seq (Cherbas et al. 2011). We find that these values are highly correlated $(R>0.8)$ for both Aub bound and Piwi bound piRNAs, indicating that mRNAs are randomly sampled for piRNA processing (Fig. 4).

\section{An Aubergine protein isoform lacking part of the $N$ terminus is expressed in early Drosophila embryos and in Kc167 but does not bind piRNAs in vivo}

The Aub-83 antibody that we previously generated was raised against a peptide corresponding to amino acid residues 73-86 of Aub (Fig. 5A; Vourekas et al. 2016). When we probed Aub83 immunoprecipitates from ovary and early embryo lysates with Aub-83 on WB, we detected a slow migrating band, corresponding in size to full-length Aub, in all samples along with a faster migrating band (Aub-S) in embryos, likely corresponding to a shorter version of Aub; and a faint band migrating between Aub and Aub-S (Fig. 5B). The intensity of these bands is drastically diminished after aub (but not EGFP, negative control) knockdowns in Kc167 cells indicating that they indeed represent Aub isoforms (Fig. 5C). Next we immunoprecipitated Aub from 0-2 $\mathrm{h}$ embryos and Kc167 using Aub-83 and 4D10, a monoclonal antibody generated by the Siomi lab (Nishida et al. 2007), and probed the immunoprecipitates with Aub-83 and 4D10. Interestingly only Aub-83 detects Aub-S (Fig. 5D), suggesting that the epitope for $4 \mathrm{D} 10$ is found within the first 72 amino acid residues of Aub. Finally, we confirmed the presence of both Aub and Aub-S by analyzing the corresponding protein bands from silver-stained gels of embryo and Kc167 Aub-83 immunoprecipitates (Supplemental Table S1). Aub-S may be produced by alternative mRNA splicing, alternative transcriptional or translational initiation or proteolytic cleavage of Aub protein. We performed 5' RACE analysis of total RNA isolated from 0-2 h embryos and Kc167 and detected the presence of an alternatively spliced $a u b$ transcript, which

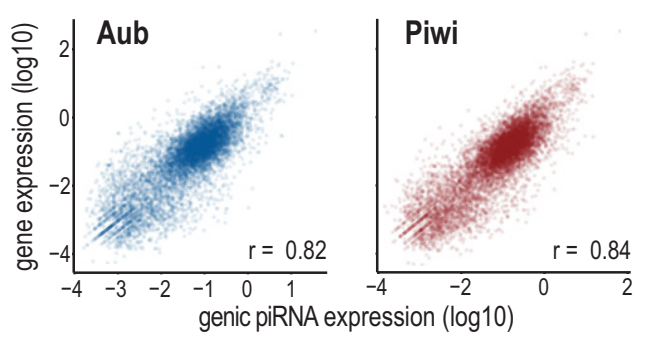

FIGURE 4. Genic piRNA abundance correlates with parent transcript abundance. Scatter plot of mRNA expression against piRNA expression for Aub and Piwi piRNAs in Kc167. we confirmed by sequencing, where the initial ATG in exon 1 was spliced out and a downstream initiation codon was used (Fig. 5E) corresponding to M72 in full-length Aub protein (Fig. 5A; Supplemental Table S2). These findings indicate that Aub-S is produced by alternative splicing but do not rule out other mechanisms, most notably proteolytic cleavage of full-length Aub.

To address whether Aub-S bind piRNAs, or other RNAs, in vivo, we performed UV-crosslinking of live Kc167 cells followed by Aub-83 immunoprecipitation (CLIP). Following on-bead dephosphorylation, we $5^{\prime}$-end radiolabeled bound RNAs, resolved them by NuPAGE and detected AubpiRNA complexes by autoradiography after nitrocellulose membrane transfer. As shown in Figure 5F, we obtained a strong and specific signal from full-length Aub but not from Aub-S, indicating that Aub-S does not bind RNAs in vivo. Since most of the signal of Aub CLIPs is derived from piRNAs (Vourekas et al. 2016), we conclude that Aub-S is not loaded with piRNAs. The N-terminal portion that is missing from Aub-S is predicted to be a disordered region that also contains the sDMAs (Fig. 5A) that bind to Tdrds. By probing Aub-83 immunoprecipitates with SYM-11, an antibody that recognizes specifically sDMAs (Kirino et al. 2009), we confirmed, as expected, that Aub-S does not contain sDMAs. Collectively, these findings suggest that the $\mathrm{N}$ terminus of Aub is important for piRNA loading and that Aub-S is an inactive Aub isoform that is unlikely to participate in piRNA related functions.

\section{DISCUSSION}

In this study we show that Kc167 cells express Aub and Piwi, which are loaded with piRNAs that are produced through a canonical primary piRNA processing pathway that involves Armi, dGasz, and Zuc. Whereas Piwi is expressed in all cells of the early embryo, Aub expression is restricted to primordial germ cells suggesting that Kc167 might be somewhat related to the germ lineage even though their gene expression signature is that of somatic, hemocyte-like progenitors. Kc167 do not express Ago3 or piRNA cluster transcripts in meaningful levels and as a consequence cannot amplify transposon related piRNAs, resulting in a piRNA population that is derived from random sampling of host cytoplasmic transcripts, notably mRNAs and tRNAs. Disruption of the ping-pong cycle in aub/ago 3 double mutant ovaries also leads to significant increase of genic and tRNA-derived piRNAs that are loaded to Piwi (Senti et al. 2015).

The high degree of correlation between the expression of parent transcripts to piRNAs indicates that any transcript that can access the piRNA processing machinery will generate piRNAs. We believe that the default state of the primary piRNA biogenesis machinery is random transcript sampling to allow generation of piRNAs from any transcript, including newly acquired retrotransposons. The piRNAs that are derived from and target transposon related sequences are 
A

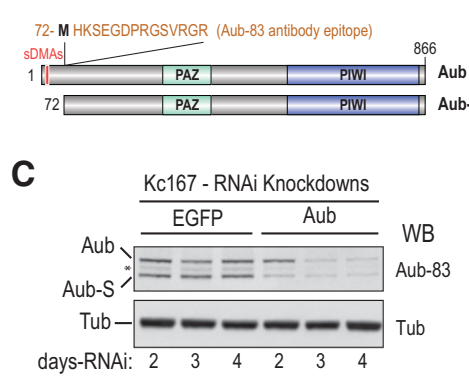

B

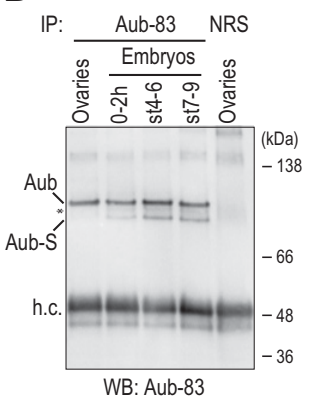

D
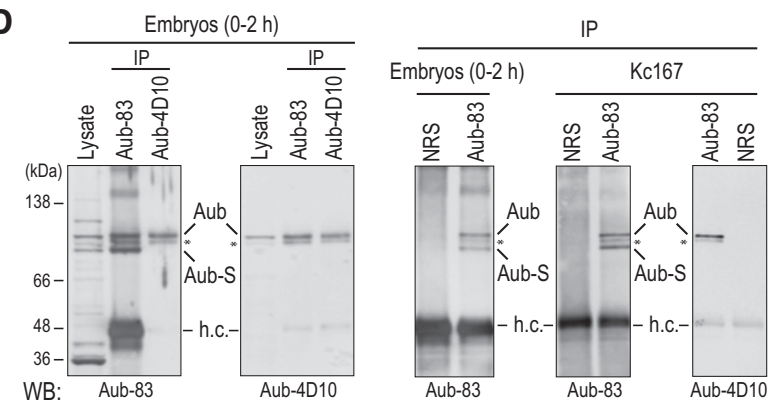

E

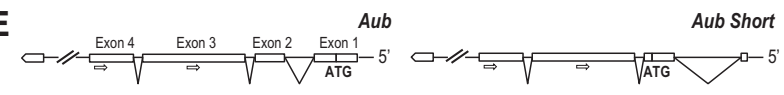

$\mathbf{F}$

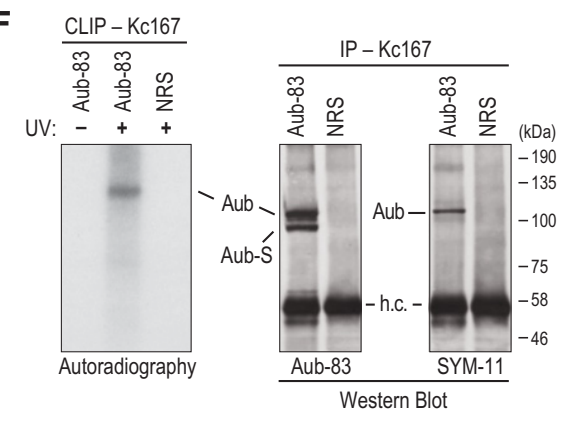

FIGURE 5. Early Drosophila embryos and Kc167 express a shorter Aub isoform, which does not bind RNA in vivo. (A) Schematic representation of full-length and short Aub polypeptides with epitope recognized by Aub- 83 antibody. The position of the symmetrically dimethylated arginine residues (sDMAs) is shown. (B) Western blot (WB) of Aub immunoprecipitates in ovarian and embryonic lysates of the indicated developmental stage. Asterisk $\left({ }^{*}\right)$ indicates a faster migrating Aub protein. (h.c.) Heavy antibody chain. (C) WB for Aub in Kc167 with EGFP or $a u b$ knockdowns; tubulin served as loading control. (D) WB for Aub in lysates or immunoprecipitates derived from $0-2 \mathrm{~h}$ embryos or Kc167. Rabbit Aub-83 and mouse Aub-4D10 antibodies were used for IP and WBs as indicated. (E) Schematic representation of full-length and short aub transcripts. Arrows indicate priming sites for oligos used in $5^{\prime}$ RACE. ( $F$ ) Aub CLIP in UV and non-UV treated Kc167. WBs for Aub and for sDMA-modified Aub (SYM-11) in Aub-83 immunoprecipitates from Kc167; NRS served as negative control.

then amplified by the ping-pong cycle, and at the same time consume transposons. This default state is unmasked in Kc167 cells likely because they do not express piRNA cluster transcripts in sufficient amounts and do not amplify transposon piRNAs. piRNA studies in Drosophila require dissection of large numbers of ovaries and testes, which is a tedious pro- cess. The use of OSC and BmN4 cell-based systems has greatly facilitated biochemical and cell biological approaches for the study of piRNAs.

However, OSC cells require fly extract for growth, while the piRNA pathway of Bombyx mori differs somewhat from that of Drosophila as only two PIWI proteins are expressed. Kc167 cells, on the other hand, are widely used, easy to propagate and transfect and very well studied. Furthermore, since most Kc167 piRNAs are genic, they can be mapped uniquely to the genome, greatly facilitating bioinformatical analyses. We expect that Kc167 will serve as an excellent system to study piRNA biogenesis and piRNA-related factors.

\section{MATERIALS AND METHODS}

\section{Kc167 and fly cultures}

Kc167 cells, obtained from DGRC, were grown in Schneider's medium (Gibco) supplemented with 10\% FBS (Sigma-Aldrich) and $2 \mathrm{mM}$ L-Glutamine (Gibco) at $25^{\circ} \mathrm{C}$. Drosophila melanogaster strain $y^{1} w^{1118}$ was used for ovary and embryo collections. Flies were grown on standard cornmeal molasses at $25^{\circ} \mathrm{C}$, with $70 \%$ relative humidity in a 12 -h light-dark cycle.

\section{Lysate preparation, Western blot, and antibodies}

Kc167 cell pellets and pestle-ground fly tissues were lysed by sonication in RSB-200 buffer containing $20 \mathrm{mM}$ Tris- $\mathrm{HCl}$ pH 7.4, 200 $\mathrm{mM} \mathrm{NaCl}, 2.5 \mathrm{mM} \mathrm{MgCl} 2,0.5 \% \mathrm{NP}-40,0.1 \%$ Triton X-100, and complete EDTA-free protease inhibitors (Roche). Lysates were precleared with centrifugation at $16,000 \mathrm{~g}$ for $20 \mathrm{~min}$ at $4^{\circ} \mathrm{C}$. Samples were mixed with SDS-loading buffer and denatured at $70^{\circ} \mathrm{C}$ for 12 min. Proteins were separated by $4 \%-12 \%$ NuPAGE Bis-Tris and blotted to nitrocellulose membranes (Invitrogen). The following antibodies were used in this study: Aub-83 (Vourekas et al. 2016), SYM11 anti-sDMA (Millipore), E7 anti- $\beta$-Tubulin (Developmental Studies Hybridoma Bank). 4D10 anti-Aub, antiAGO3, anti-Armi, and anti-Tudor antibodies were a gift from Dr. Mikiko Siomi. Piwi-N7 and Vasa-2 antibodies were produced by immunizing rabbits with the following synthetic peptides: Piwi (MADDQGRGRRRPLNED); Vasa-2 (KREFYIPPEPSNDA). Both were conjugated to KLH protein. Sera were affinity purified with columns containing the immobilized peptides (Genscript). PiwiN7 successfully detected and immunoprecipitated Piwi protein and associated piRNAs in ovary, embryo, Kc167, and OSC lysates (Fig. 1A-C; Supplemental Fig. S3A-E). Similarly, Vasa-2 antibody detected and immunoprecipitated Vasa protein in ovary lysate (Supplemental Fig. 3F).

\section{Kc167 immunostaining}

Kc167 cells from $60 \%$ confluent plates were let to adhere on poly-Llysine coated slides for $30 \mathrm{~min}$. The medium was removed and cells were fixed with $2 \%$ formaldehyde in PBS, for $15 \mathrm{~min}$. After three rinses in PBS, cells were incubated with PBT $(0.2 \%$ Triton-X, $0.5 \%$ BSA in PBS), for 30 min. Primary antibody incubation was performed overnight at $4^{\circ} \mathrm{C}$ with $1 \mathrm{ng} / \mu \mathrm{L}$ Aub-4D10 in PBT. After 
three 5 min washes in PBS, secondary antibody incubation proceeded for $1 \mathrm{~h}$ at room temperature with Alexa Fluor 594 anti-mouse antibody (Life Technologies) at 1:1000 dilution in PBT. After three 5 min washes in PBS, the cells were mounted in ProLong Gold with DAPI (Life Technologies). Kc167 cells were imaged on Leica TCS SPE confocal microscope.

\section{Immunoprecipitation and RNA isolation}

Protein $\mathrm{G}$ agarose beads (Life Technologies) were mixed with $4 \mu \mathrm{g}$ antibody or nonimmune rabbit serum for $90 \mathrm{~min}$ at $4^{\circ} \mathrm{C}$. Precleared lysates were incubated with antibody-bound beads for $90 \mathrm{~min}$ at $4^{\circ} \mathrm{C}$. After four $5 \mathrm{~min}$ washes in lysis buffer, the protein load was eluted by heating in SDS-loading buffer and separated with $4 \%-12 \%$ NuPAGE Bis-Tris. Protein bands were visualized with silver staining, excised, and sent for mass spectrometry. The same steps were followed for RNA-IP with the addition of $0.2 \mathrm{U} /$ $\mu \mathrm{L}$ RNAse inhibitor (Promega) in the lysis buffer. After the last IP wash, a $10 \%$ fraction of beads was kept for WB analysis and the rest was mixed with TRIzol reagent (Ambion). RNA isolation, dephosphorylation, and labeling were conducted as previously published (Kirino et al. 2011).

\section{Small RNA library construction}

Radiolabeled piRNAs from Aub and Piwi immunoprecipitates were resolved and purified with $8 \mathrm{M}$ Urea 15\% PAGE. Recovered RNA was ligated to a modified miRCat $3^{\prime}$ Linker-1 (IDT) containing eight extra random nucleotides at the $5^{\prime}$-end. Ligation was performed in the presence of 25\% PEG 8000 (Munafo and Robb 2010) with T4 RNA Ligase 2 Truncated K227Q (NEB). Ligated RNA was PAGE purified and reverse transcribed by a $5^{\prime}$ phosphorylated RT primer containing $3^{\prime}$ and $5^{\prime}$ adaptor complementary sequences (Ingolia et al. 2013). RT primer and RNA were heated at $65^{\circ} \mathrm{C}$ for $10 \mathrm{~min}$ and cooled down at room temperature for $5 \mathrm{~min}$. Reverse transcription (Affinityscript, Stratagene) was performed in the presence of $\left[a^{32} \mathrm{P}\right]$ ATP. cDNA was PAGE purified and circularized with CircLigase I (Epicentre). Next, cDNA was PCR amplified with Phusion DNA polymerase (NEB) and primers adding p5 and p7 flow cell binding sites on both sides of every amplicon. Signal was reamplified with a second PCR round, then size selected on 3\% metaphor gel (Lonza) and sequenced on hiSeq-50SR. The oligonucleotides used for small RNA library construction are listed in Supplemental Table S3.

\section{dsRNA preparation and transfection}

Primer sequences fused to T7 promoter (Supplemental Table S4) were used for the PCR amplification of 300-500-bp gene fragments. Amplicons served as templates for in vitro transcription with the T7 Megascript kit (Ambion). Purified RNA was denatured at $65^{\circ} \mathrm{C}$ for $30 \mathrm{~min}$ and slowly cooled down to $37^{\circ} \mathrm{C}$ before stored at $-20^{\circ} \mathrm{C}$. For gene knockdown experiments, dsRNA was delivered into Kc167 with Effectene transfection reagent (Qiagen) (Zhou et al. 2013). For every million cells seeded, $1 \mu \mathrm{g}$ dsRNA was mixed in $100 \mu \mathrm{L}$ EC buffer, $8 \mu \mathrm{L}$ Enhancer, and $4 \mu \mathrm{L}$ Effectene. Transfected cells were incubated at $25^{\circ} \mathrm{C}$ for $3 \mathrm{~d}$ and then subjected to a second round of dsRNA transfection.

\section{qRT-PCR, Northern blot, and 5' RACE}

Total RNA was extracted from Kc167 pellets or 0-2 h embryos with TRIzol reagent (Ambion) and treated with RQ1 DNAse. For qRTPCR, $1 \mu \mathrm{g}$ total RNA was reverse transcribed with random hexamers by Superscript III (Invitrogen). cDNA was amplified using FastStart Universal SYBR Green Master ROX (Roche) and custom designed primers (Supplemental Table S5). Assays were run on StepOnePlus Real-Time PCR system (Applied Biosystems) using the $\Delta \Delta \mathrm{Ct}$ method and Gapdh2 as loading control. For NB, $10 \mu \mathrm{g}$ total RNA was separated by $8 \mathrm{M}$ urea 15 or $17.5 \%$ PAGE and transferred to Hybond-N+ membranes (GE Healthcare). Blotted RNA was hybridized with $\left[\gamma^{-}{ }^{32} \mathrm{P}\right]$ ATP labeled DNA oligonucleotides antisense to tRNA sequences (Supplemental Table S6). For 5' RACE, $10 \mu \mathrm{g}$ total RNA was used as starting material, following the instructions of the FirstChoice RLM-RACE kit (Ambion). The Aub specific primers designed for 5' RACE analysis are listed in Supplemental Table S7.

\section{CLIP}

Each CLIP sample was generated using two confluent $10 \mathrm{~cm}$ plates of live Kc167 resuspended in $8 \mathrm{~mL}$ cold HBSS (Gibco). Cells were crosslinked with $400 \mathrm{~mJ} / \mathrm{cm}^{2}, 265 \mathrm{~nm}$ ultraviolet light, three times with 30 sec intervals. Cells were centrifuged at $1200 \mathrm{~g}$ for $10 \mathrm{~min}$ at $4^{\circ} \mathrm{C}$ and washed in $1 \mathrm{~mL}$ cold PBS. After a second centrifugation step at $1000 \mathrm{~g}$ for $1 \mathrm{~min}$ at $4^{\circ} \mathrm{C}$, cells pellets were flash frozen in liquid nitrogen and stored at $-80^{\circ} \mathrm{C}$. Cell lysate preparation, antibody binding, and IP were performed exactly as described previously (Vourekas and Mourelatos 2014; Vourekas et al. 2016). After IP washes the bead-bound immunoprecipitate was dephosphorylated (Antarctic Phosphatase, NEB) and on-bead labeled (T4 PNK, NEB) with $\left[\gamma^{-32} \mathrm{P}\right]$ ATP. The beads were washed five times and the RNA and protein samples were eluted by heating in SDS-loading buffer. Samples were resolved by $4 \%-12 \%$ NuPAGE Bis-Tris, transferred to nitrocellulose membrane and visualized by autoradiography.

\section{Read processing and alignment}

The 3 '-end adaptor sequence was trimmed from the reads using the cutadapt software with parameters -m 15 -e 0.25 . An additional collapsing step was performed for libraries that have an $8 \mathrm{~N}$ random barcode. In this step reads with the same sequence were collapsed and only one was retained. Afterwards, the $8 \mathrm{~N}$ barcode was removed. For the collapsing step we used the CLIPSeqTools software (Maragkakis et al. 2016). Reads were aligned to the Drosophila melanogaster genome $(\mathrm{dm} 3)$ using the STAR aligner version 2.4.2 using the following parameters -outFilterMultimapScoreRange 0 -alignIntronMax 50000 -outFilterIntronMotifs RemoveNoncanonicalUnannotated -outFilterMatchNmin 15 -outFilterMatchNminOverLread 0.9 -sjdbOverhang 50 and a reference gene model annotation file that was downloaded from UCSC. Aligned reads were loaded into a SQLite3 database for further processing with CLIPSeqTools and were annotated with information whether they are contained within any elements from RepeatMasker (downloaded from UCSC), rRNAs (extracted from UCSC gene model annotation file), tRNAs (downloaded from FlyBase r5.57), piRNA clusters ( flam and $42 \mathrm{AB}$ ), and genes (from UCSC gene model annotation file). 


\section{Kc167 gene expression}

RNA-seq data for Kc167 gene expression were downloaded from (Cherbas et al. 2011). Reads were aligned to $\mathrm{dm} 3$ and were further processed and annotated using CLIPSeqTools and the same pipeline as small RNA libraries. Gene counts were calculated using CLIPSeqTools. To avoid zero values the smallest count per nucleotide was added to all values. The Pearson correlation coefficient between the IP libraries and the expression was calculated using the cor function in $R$.

\section{DATA DEPOSITION}

Sequencing data have been deposited into the Sequence Read Archive (SRA), project ID PRJNA349037.

\section{SUPPLEMENTAL MATERIAL}

Supplemental material is available for this article.

\section{ACKNOWLEDGMENTS}

We thank M. Siomi (University of Tokyo) for providing antibodies and F. Ibrahim and A. Vourekas for discussions and advice. This work was supported by a Brody family fellowship to M.M. and National Institutes of Health (NIH) grant GM072777 to Z.M.

Received September 7, 2016; accepted October 22, 2016.

\section{REFERENCES}

Aravin AA, Lagos-Quintana M, Yalcin A, Zavolan M, Marks D, Snyder B, Gaasterland T, Meyer J, Tuschl T. 2003. The small RNA profile during Drosophila melanogaster development. Dev Cell 5: 337-350.

Brennecke J, Aravin AA, Stark A, Dus M, Kellis M, Sachidanandam R, Hannon GJ. 2007. Discrete small RNA-generating loci as master regulators of transposon activity in Drosophila. Cell 128: 1089-1103.

Brennecke J, Malone CD, Aravin AA, Sachidanandam R, Stark A, Hannon GJ. 2008. An epigenetic role for maternally inherited piRNAs in transposon silencing. Science 322: 1387-1392.

Brown JB, Celniker SE. 2015. Lessons from modENCODE. Annu Rev Genomics Hum Genet 16: 31-53.

Chen C, Nott TJ, Jin J, Pawson T. 2011. Deciphering arginine methylation: tudor tells the tale. Nat Rev Mol Cell Biol 12: 629-642.

Cherbas L, Willingham A, Zhang D, Yang L, Zou Y, Eads BD, Carlson JW, Landolin JM, Kapranov P, Dumais J, et al. 2011. The transcriptional diversity of 25 Drosophila cell lines. Genome Res 21: 301-314.

Cook HA, Koppetsch BS, Wu J, Theurkauf WE. 2004. The Drosophila SDE3 homolog armitage is required for oskar mRNA silencing and embryonic axis specification. Cell 116: 817-829.

Cox DN, Chao A, Baker J, Chang L, Qiao D, Lin H. 1998. A novel class of evolutionarily conserved genes defined by piwi are essential for stem cell self-renewal. Genes Dev 12: 3715-3727.

Czech B, Hannon GJ. 2016. One loop to rule them all: the ping-pong cycle and piRNA-guided silencing. Trends Biochem Sci 41: 324-337.

de Vanssay A, Bouge AL, Boivin A, Hermant C, Teysset L, Delmarre V, Antoniewski C, Ronsseray S. 2012. Paramutation in Drosophila linked to emergence of a piRNA-producing locus. Nature 490: $112-115$.
Eaton ML, Prinz JA, MacAlpine HK, Tretyakov G, Kharchenko PV, MacAlpine DM. 2011. Chromatin signatures of the Drosophila replication program. Genome Res 21: 164-174.

Echalier G, Ohanessian A. 1969. Isolation, in tissue culture, of Drosophila melangaster cell lines. C R Acad Sci Hebd Seances Acad Sci D 268: 1771-1773.

Fagegaltier D, Falciatori I, Czech B, Castel S, Perrimon N, Simcox A, Hannon GJ. 2016. Oncogenic transformation of Drosophila somatic cells induces a functional piRNA pathway. Genes Dev 30: 1623-1635.

Frost RJ, Hamra FK, Richardson JA, Qi X, Bassel-Duby R, Olson EN. 2010. MOV10L1 is necessary for protection of spermatocytes against retrotransposons by Piwi-interacting RNAs. Proc Natl Acad Sci 107: 11847-11852.

Gunawardane LS, Saito K, Nishida KM, Miyoshi K, Kawamura Y, Nagami T, Siomi H, Siomi MC. 2007. A slicer-mediated mechanism for repeat-associated siRNA $5^{\prime}$ end formation in Drosophila. Science 315: $1587-1590$.

Haase AD, Fenoglio S, Muerdter F, Guzzardo PM, Czech B, Pappin DJ, Chen C, Gordon A, Hannon GJ. 2010. Probing the initiation and effector phases of the somatic piRNA pathway in Drosophila. Genes Dev 24: 2499-2504.

Han BW, Wang W, Li C, Weng Z, Zamore PD. 2015. Noncoding RNA. piRNA-guided transposon cleavage initiates Zucchini-dependent, phased piRNA production. Science 348: 817-821.

Handler D, Meixner K, Pizka M, Lauss K, Schmied C, Gruber FS, Brennecke J. 2013. The genetic makeup of the Drosophila piRNA pathway. Mol Cell 50: 762-777.

Harris AN, Macdonald PM. 2001. Aubergine encodes a Drosophila polar granule component required for pole cell formation and related to eIF2C. Development 128: 2823-2832.

Herold N, Will CL, Wolf E, Kastner B, Urlaub H, Luhrmann R. 2009. Conservation of the protein composition and electron microscopy structure of Drosophila melanogaster and human spliceosomal complexes. Mol Cell Biol 29: 281-301.

Hirakata S, Siomi MC. 2016. piRNA biogenesis in the germline: from transcription of piRNA genomic sources to piRNA maturation. Biochim Biophys Acta 1859: 82-92.

Homolka D, Pandey RR, Goriaux C, Brasset E, Vaury C, Sachidanandam R, Fauvarque MO, Pillai RS. 2015. PIWI slicing and RNA elements in precursors instruct directional primary piRNA biogenesis. Cell Rep 12: 418-428.

Honda S, Kirino Y, Maragkakis M, Alexiou P, Ohtaki A, Murali R, Mourelatos Z. 2013. Mitochondrial protein BmPAPI modulates the length of mature piRNAs. RNA 19: 1405-1418.

Horwich MD, Li C, Matranga C, Vagin V, Farley G, Wang P, Zamore PD. 2007. The Drosophila RNA methyltransferase, DmHen1, modifies germline piRNAs and single-stranded siRNAs in RISC. Curr Biol 17: 1265-1272.

Huang H, Gao Q, Peng X, Choi SY, Sarma K, Ren H, Morris AJ, Frohman MA. 2011. piRNA-associated germline nuage formation and spermatogenesis require MitoPLD profusogenic mitochondrial-surface lipid signaling. Dev Cell 20: 376-387.

Illmensee K, Mahowald AP. 1974. Transplantation of posterior polar plasm in Drosophila. Induction of germ cells at the anterior pole of the egg. Proc Natl Acad Sci 71: 1016-1020.

Ingolia NT, Brar GA, Rouskin S, McGeachy AM, Weissman JS. 2013. Genome-wide annotation and quantitation of translation by ribosome profiling. Curr Protoc Mol Biol 103: 4.18.1-4.18.19.

Ipsaro JJ, Haase AD, Knott SR, Joshua-Tor L, Hannon GJ. 2012. The structural biochemistry of Zucchini implicates it as a nuclease in piRNA biogenesis. Nature 491: 279-283.

Iwasaki YW, Murano K, Ishizu H, Shibuya A, Iyoda Y, Siomi MC, Siomi H, Saito K. 2016. Piwi modulates chromatin accessibility by regulating multiple factors including histone $\mathrm{H} 1$ to repress transposons. Mol Cell 63: 408-419.

Izumi N, Shoji K, Sakaguchi Y, Honda S, Kirino Y, Suzuki T, Katsuma S, Tomari Y. 2016. Identification and functional analysis of the prepiRNA 3' Trimmer in silkworms. Cell 164: 962-973. 
Janic A, Mendizabal L, Llamazares S, Rossell D, Gonzalez C. 2010. Ectopic expression of germline genes drives malignant brain tumor growth in Drosophila. Science 330: 1824-1827.

Kawaoka S, Hayashi N, Suzuki Y, Abe H, Sugano S, Tomari Y, Shimada T, Katsuma S. 2009. The Bombyx ovary-derived cell line endogenously expresses PIWI/PIWI-interacting RNA complexes. RNA 15: 1258-1264.

Kirino Y, Mourelatos Z. 2007a. The mouse homolog of HEN1 is a potential methylase for Piwi-interacting RNAs. RNA 13: 1397-1401.

Kirino Y, Mourelatos Z. 2007b. Mouse Piwi-interacting RNAs are 2'-Omethylated at their $3^{\prime}$ termini. Nat Struct Mol Biol 14: 347-348.

Kirino Y, Kim N, de Planell-Saguer M, Khandros E, Chiorean S, Klein PS, Rigoutsos I, Jongens TA, Mourelatos Z. 2009. Arginine methylation of Piwi proteins catalysed by dPRMT5 is required for Ago3 and Aub stability. Nat Cell Biol 11: 652-658.

Kirino Y, Vourekas A, Sayed N, de Lima Alves F, Thomson T, Lasko P, Rappsilber J, Jongens TA, Mourelatos Z. 2010. Arginine methylation of Aubergine mediates Tudor binding and germ plasm localization. RNA 16: 70-78.

Kirino Y, Vourekas A, Khandros E, Mourelatos Z. 2011. Immunoprecipitation of piRNPs and directional, next generation sequencing of piRNAs. Methods Mol Biol 725: 281-293.

Lau NC, Robine N, Martin R, Chung WJ, Niki Y, Berezikov E, Lai EC. 2009. Abundant primary piRNAs, endo-siRNAs, and microRNAs in a Drosophila ovary cell line. Genome Res 19: 1776-1785.

Lehmann R, Ephrussi A. 1994. Germ plasm formation and germ cell determination in Drosophila. Ciba Found Symp 182: 282-296; discussion 296-300.

Li C, Vagin VV, Lee S, Xu J, Ma S, Xi H, Seitz H, Horwich MD, Syrzycka M, Honda BM, et al. 2009. Collapse of germline piRNAs in the absence of Argonaute 3 reveals somatic piRNAs in flies. Cell 137: 509-521.

Lim SL, Qu ZP, Kortschak RD, Lawrence DM, Geoghegan J, Hempfling AL, Bergmann M, Goodnow CC, Ormandy CJ, Wong L, et al. 2015. HENMT1 and piRNA stability are required for adult male germ cell transposon repression and to define the spermatogenic program in the mouse. PLoS Genet 11: e1005620.

Liu H, Wang JY, Huang Y, Li Z, Gong W, Lehmann R, Xu RM. 2010. Structural basis for methylarginine-dependent recognition of Aubergine by Tudor. Genes Dev 24: 1876-1881.

Liu X, Zheng Q, Vrettos N, Maragkakis M, Alexiou P, Gregory BD, Mourelatos Z. 2014. A microRNA precursor surveillance system in quality control of microRNA synthesis. Mol Cell 55: 868-879.

Ma L, Buchold GM, Greenbaum MP, Roy A, Burns KH, Zhu H, Han DY, Harris RA, Coarfa C, Gunaratne PH, et al. 2009. GASZ is essential for male meiosis and suppression of retrotransposon expression in the male germline. PLoS Genet 5: e1000635.

Malone CD, Brennecke J, Dus M, Stark A, McCombie WR, Sachidanandam R, Hannon GJ. 2009. Specialized piRNA pathways act in germline and somatic tissues of the Drosophila ovary. Cell 137: 522-535.

Maragkakis M, Alexiou P, Nakaya T, Mourelatos Z. 2016. CLIPSeqTools - a novel bioinformatics CLIP-seq analysis suite. RNA 22: 1-9.

Mevel-Ninio M, Pelisson A, Kinder J, Campos AR, Bucheton A. 2007. The flamenco locus controls the gypsy and ZAM retroviruses and is required for Drosophila oogenesis. Genetics 175: 1615-1624.

Mohn F, Handler D, Brennecke J. 2015. Noncoding RNA. piRNA-guided slicing specifies transcripts for Zucchini-dependent, phased piRNA biogenesis. Science 348: 812-817.

Munafo DB, Robb GB. 2010. Optimization of enzymatic reaction conditions for generating representative pools of cDNA from small RNA. RNA 16: 2537-2552.

Niki Y, Yamaguchi T, Mahowald AP. 2006. Establishment of stable cell lines of Drosophila germ-line stem cells. Proc Natl Acad Sci 103: 16325-16330.

Nishida KM, Saito K, Mori T, Kawamura Y, Nagami-Okada T, Inagaki S, Siomi H, Siomi MC. 2007. Gene silencing mechanisms mediated by Aubergine piRNA complexes in Drosophila male gonad. RNA 13: 1911-1922.
Nishida KM, Okada TN, Kawamura T, Mituyama T, Kawamura Y, Inagaki S, Huang H, Chen D, Kodama T, Siomi H, et al. 2009. Functional involvement of Tudor and dPRMT5 in the piRNA processing pathway in Drosophila germlines. EMBO J 28: 3820-3831.

Nishimasu H, Ishizu H, Saito K, Fukuhara S, Kamatani MK, Bonnefond L, Matsumoto N, Nishizawa T, Nakanaga K, Aoki J, et al. 2012. Structure and function of Zucchini endoribonuclease in piRNA biogenesis. Nature 491: 284-287.

Ohara T, Sakaguchi Y, Suzuki T, Ueda H, Miyauchi K, Suzuki T. 2007. The $3^{\prime}$ termini of mouse Piwi-interacting RNAs are 2'-O-methylated. Nat Struct Mol Biol 14: 349-350.

Olivieri D, Sykora MM, Sachidanandam R, Mechtler K, Brennecke J. 2010. An in vivo RNAi assay identifies major genetic and cellular requirements for primary piRNA biogenesis in Drosophila. EMBO J 29: 3301-3317.

Pane A, Wehr K, Schupbach T. 2007. zucchini and squash encode two putative nucleases required for rasiRNA production in the Drosophila germline. Dev Cell 12: 851-862.

Pek JW, Anand A, Kai T. 2012. Tudor domain proteins in development. Development 139: 2255-2266.

Rangan P, DeGennaro M, Jaime-Bustamante K, Coux RX, Martinho RG, Lehmann R. 2009. Temporal and spatial control of germ-plasm RNAs. Curr Biol 19: 72-77.

Saito K, Sakaguchi Y, Suzuki T, Suzuki T, Siomi H, Siomi MC. 2007. Pimet, the Drosophila homolog of HEN1, mediates 2'-O-methylation of Piwi-interacting RNAs at their 3' ends. Genes Dev 21: 1603-1608.

Saito K, Inagaki S, Mituyama T, Kawamura Y, Ono Y, Sakota E, Kotani H, Asai K, Siomi H, Siomi MC. 2009. A regulatory circuit for piwi by the large Maf gene traffic jam in Drosophila. Nature 461: 1296-1299.

Saito K, Ishizu H, Komai M, Kotani H, Kawamura Y, Nishida KM, Siomi H, Siomi MC. 2010. Roles for the Yb body components Armitage and $\mathrm{Yb}$ in primary piRNA biogenesis in Drosophila. Genes Dev 24: 2493-2498.

Sato K, Iwasaki YW, Shibuya A, Carninci P, Tsuchizawa Y, Ishizu H, Siomi MC, Siomi H. 2015. Krimper enforces an antisense bias on piRNA pools by binding AGO3 in the Drosophila germline. Mol Cell 59: 553-563.

Saxe JP, Chen M, Zhao H, Lin H. 2013. Tdrkh is essential for spermatogenesis and participates in primary piRNA biogenesis in the germline. $E M B O J$ 32: 1869-1885.

Senti KA, Jurczak D, Sachidanandam R, Brennecke J. 2015. piRNAguided slicing of transposon transcripts enforces their transcriptional silencing via specifying the nuclear piRNA repertoire. Genes Dev 29: $1747-1762$.

Sienski G, Batki J, Senti KA, Donertas D, Tirian L, Meixner K, Brennecke J. 2015. Silencio/CG9754 connects the Piwi-piRNA complex to the cellular heterochromatin machinery. Genes Dev 29: 2258-2271.

Siomi MC, Mannen T, Siomi H. 2010. How does the royal family of Tudor rule the PIWI-interacting RNA pathway? Genes Dev 24: 636-646.

Siomi MC, Sato K, Pezic D, Aravin AA. 2011. PIWI-interacting small RNAs: the vanguard of genome defence. Nat Rev Mol Cell Biol 12: 246-258.

Sumiyoshi T, Sato K, Yamamoto H, Iwasaki YW, Siomi H, Siomi MC. 2016. Loss of l(3)mbt leads to acquisition of the ping-pong cycle in Drosophila ovarian somatic cells. Genes Dev 30: 1617-1622.

Vagin VV, Sigova A, Li C, Seitz H, Gvozdev V, Zamore PD. 2006. A distinct small RNA pathway silences selfish genetic elements in the germline. Science 313: 320-324.

Vourekas A, Mourelatos Z. 2014. HITS-CLIP (CLIP-Seq) for mouse Piwi proteins. Methods Mol Biol 1093: 73-95.

Vourekas A, Zheng K, Fu Q, Maragkakis M, Alexiou P, Ma J, Pillai RS, Mourelatos Z, Wang PJ. 2015. The RNA helicase MOV10L1 binds piRNA precursors to initiate piRNA processing. Genes Dev 29: 617-629.

Vourekas A, Alexiou P, Vrettos N, Maragkakis M, Mourelatos Z. 2016. Sequence-dependent but not sequence-specific piRNA adhesion traps mRNAs to the germ plasm. Nature 531: 390-394. 
Wang H, Ma Z, Niu K, Xiao Y, Wu X, Pan C, Zhao Y, Wang K, Zhang Y, Liu N. 2016. Antagonistic roles of Nibbler and Hen1 in modulating piRNA $3^{\prime}$ ends in Drosophila. Development 143: 530-539.

Watanabe T, Chuma S, Yamamoto Y, Kuramochi-Miyagawa S, Totoki Y, Toyoda A, Hoki Y, Fujiyama A, Shibata T, Sado T, et al. 2011. MITOPLD is a mitochondrial protein essential for nuage formation and piRNA biogenesis in the mouse germline. Dev Cell 20: 364-375.

Webster A, Li S, Hur JK, Wachsmuth M, Bois JS, Perkins EM, Patel DJ, Aravin AA. 2015. Aub and Ago3 are recruited to nuage through two mechanisms to form a ping-pong complex assembled by krimper. Mol Cell 59: 564-575.

Williamson A, Lehmann R. 1996. Germ cell development in Drosophila. Annu Rev Cell Dev Biol 12: 365-391.
Yin Z, Sadok A, Sailem H, McCarthy A, Xia X, Li F, Garcia MA, Evans L, Barr AR, Perrimon N, et al. 2013. A screen for morphological complexity identifies regulators of switch-like transitions between discrete cell shapes. Nat Cell Biol 15: 860-871.

Yu B, Yang Z, Li J, Minakhina S, Yang M, Padgett RW, Steward R, Chen X. 2005. Methylation as a crucial step in plant microRNA biogenesis. Science 307: 932-935.

Zheng K, Xiol J, Reuter M, Eckardt S, Leu NA, McLaughlin KJ, Stark A, Sachidanandam R, Pillai RS, Wang PJ. 2010. Mouse MOV10L1 associates with Piwi proteins and is an essential component of the Piwiinteracting RNA (piRNA) pathway. Proc Natl Acad Sci 107: 11841-11846.

Zhou R, Mohr S, Hannon GJ, Perrimon N. 2013. Inducing RNAi in Drosophila cells by transfection with dsRNA. Cold Spring Harb Protoc 2013: 461-463. 

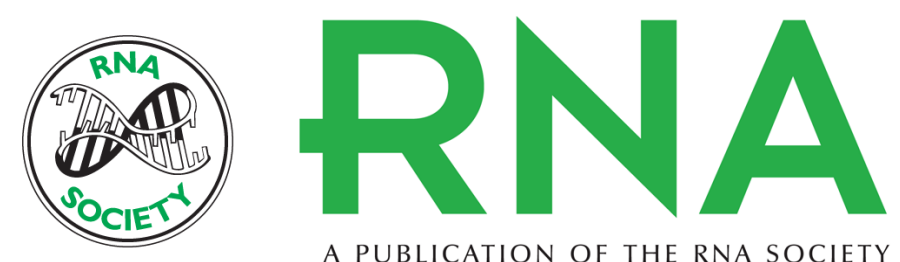

A PUBLICATION OF THE RNA SOCIETY

\section{Kc167, a widely used Drosophila cell line, contains an active primary piRNA pathway}

Nicholas Vrettos, Manolis Maragkakis, Panagiotis Alexiou, et al.

RNA 2017 23: 108-118 originally published online October 27, 2016

Access the most recent version at doi:10.1261/rna.059139.116

\section{Supplemental http://rnajournal.cshlp.org/content/suppl/2016/10/27/rna.059139.116.DC1 Material}

References This article cites 80 articles, 40 of which can be accessed free at: http://rnajournal.cshlp.org/content/23/1/108.full.html\#ref-list-1

Creative This article is distributed exclusively by the RNA Society for the first 12 months after the Commons License full-issue publication date (see http://rnajournal.cshlp.org/site/misc/terms.xhtml). After 12 months, it is available under a Creative Commons License (Attribution-NonCommercial 4.0 International), as described at http://creativecommons.org/licenses/by-nc/4.0/.

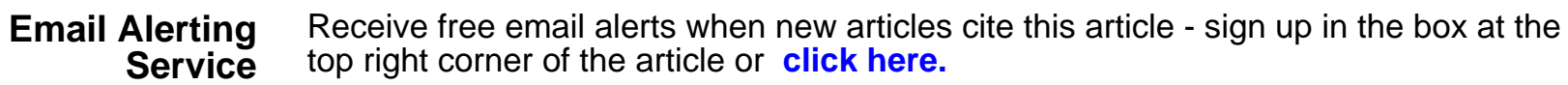

